\title{
Triple assessment for addressing trio-pathy in diabetic foot - Rapid screening tool for amputation prevention in govt. Hospital setting
}

\author{
Rajesh Prajapati ${ }^{1}$, Manisha Singh $^{2, *}$, Devesh Verma ${ }^{3}$ \\ ${ }^{1,2}$ Associate Professor, ${ }^{3}$ Senior Resident, Dept. of Surgery, Gajra Raja Medical College, Gwalior, Madhya Pradesh, India
}

*Corresponding Author: Manisha Singh

Email: rsjadaun62@gmail.com

\begin{abstract}
Introduction: The present study was done to perform foot examination using Amit Jain's Triple Assessment screening tool on in-patients in surgical wards.

Materials and Methods: A descriptive retrospective study was done at Gajra Raja Medical College, Gwalior (M.P.) in department of surgery during a period from April 2018 to June 2018 on patients of diabetic foot admitted in all six units of surgical wards.

Results: A total of 72 patients were included in this study as per search in case records. Majority of patients had diabetes of more than ten years duration and males were more commonly affected. All patients had diagnosis of diabetic foot with varied spectrum of associated lesions alone or in combination. Surgical debridement $(66.66 \%)$ was the commonest procedure done in these patients. The affected foot of all patients was examined, with component assessment of feeling pedal pulses done in $86.11 \%$ cases and testing for sensation was done in $25 \%$ cases. In contralateral foot $58 \%$ patients were examined, in similar percentage pedal pulses were examined and foot sensations were not tested in any of them.

Conclusion: Despite foot examination being of paramount importance it is often incomplete and inadequate in diabetic foot subjects as is also evident from observations of present study. Amit Jain's Triple assessment of diabetic feet is a rapid inexpensive screening tool for obtaining basic foot information in order to segregate at risk feet and offer preventive care against amputation.
\end{abstract}

Keywords: Amit Jain, Assessment, Triple, Diabetic foot, Trio-pathy, Screening, High risk foot.

\section{Introduction}

Diabetes mellitus is the most common metabolic disease of twenty first century which has registered growth in epidemic proportions affecting around 366 million people across the globe. ${ }^{1}$ One of the most devastating complications of diabetes are those involving feet, which commence with onset of loss of protective sensation or diabetic neuropathy. In $80 \%$ of diabetic patients with trophic ulcers there in lack of protective sensation. In diabetic neuropathic subjects the risk of developing foot ulcer almost doubles to $4.5 \%$ compared to only $2 \%$ risk in a diabetic without neuropathy.

Presence of diabetes related trio-pathy of neuropathy (peripheral and autonomic), vasculopathy, immunopathy with infection predisposes to ulceration and eventually amputation. ${ }^{2}$ It is well known fact that a diabetic individual has $15-25 \%$ life time chance of developing foot ulcer of which more than half get infected and $50-70 \%$ recur over ensuing five years. ${ }^{3}$ Approximately $85 \%$ cases of non traumatic lower limb amputation have a history of diabetic foot ulceration as the presence of diabetes is associated with 20 fold higher risk of lower extremity loss. Diabetic foot ulcer undergoing amputation is linked to about 50\% mortality rate, which is twice that in a person without diabetic foot ulcer; and even worse prognosis than breast or prostate cancer. ${ }^{4}$

The treatment of foot ulcers and related amputations may be economically draining to the diabetic patients due to direct treatment costs and indirect costs in terms of loss of work productivity. ${ }^{5}$ Recent years have witnessed a sharp decline in number of major amputation in diabetic patients owing to excellent preventive education, screening programmes and targeted therapy at diabetic foot speciality clinic. The preventive programmes focus on screening of high risk foot due to diabetic neuropathy, which is the earliest identifiable point in amputation cascade.

Routine complete foot evaluation by a clinician or paramedical staff may be incomplete or even missed in $80 \%$ of cases owing to lack of time or inadequate training. ${ }^{6}$ It is essential to perform comprehensive foot workup in order to reduce foot related problems in diabetic patients.

In-Low's 60 second diabetic foot screening, ${ }^{7}$ simplified 60 second diabetic foot screening ${ }^{8}$ and Amit Jain's Triple assessment ${ }^{9}$ for diabetic foot are few comprehensive screening tools specifically for diabetic foot.

The aim of conducting present study was two fold - firstly to evaluate adequacy of foot examination done in surgical inpatients by treating surgeons according to Amit Jain's triple assessment - look, feel and test component tools and secondly to establish the efficacy of this new screening tool. Amit Jain's triple assessment is a rapid, simplified novel screening method for diabetic foot from Asian continent for early recognition of diabetic foot trio-pathy and check progression of high risk feet to amputation. This screening method fulfills most criteria laid down for ideal screening test, is simple, very practical, 
acceptable, cost effective and endowed with repeatability in hands of different health care professionals from different regions.

\section{Materials and Methods}

A descriptive retrospective study was done in Department of surgery at Gajra Raja Medical College, Gwalior (M.P.) India for a period from April 2018 to June 2018. Data were collected from central admission register and case records of each surgical unit. The inclusion and exclusion criteria for our study were as follows:

\section{Inclusion Criteria}

1. Diabetic foot patients with type $2 \mathrm{DM}$ admitted in all six units of general surgery wards of our hospital.

2. Referred cases of diabetic foot in our hospital operated else where.

\section{Exclusion Criteria}

1. Patients with type 1 diabetes.

2. Diabetic foot patients admitted in medical wards, ICU or in other departments.

3. Diabetic foot patients who died during treatment or referred to other wards

4. Patients in whom records were not available.

We did evaluation of diabetic feet using Amit Jains Triple assessment and studied the three components of look, feel and test in our study. Identification of ulcer, infection or preulcer callus or scar by inspection of dorsum of foot, sole and interdigital spaces was done for look component of screening. For feel component palpation of dorsalis pedis, anterior tibial artery and posterior tibial artery was done with aim to detect ischemia. For Test component we utilized monofilament test and/or tuning fork to assess touch and vibration sensation respectively. We analysed the data obtained using mean and percentage values. This study was approved by our institution ethics committee.

\section{Results}

A total of 70 consecutive subjects who were admitted to all six units of surgical wards were recruited for this study. There were 49 males (68\%) and 23 females (32\%). Fig. 1

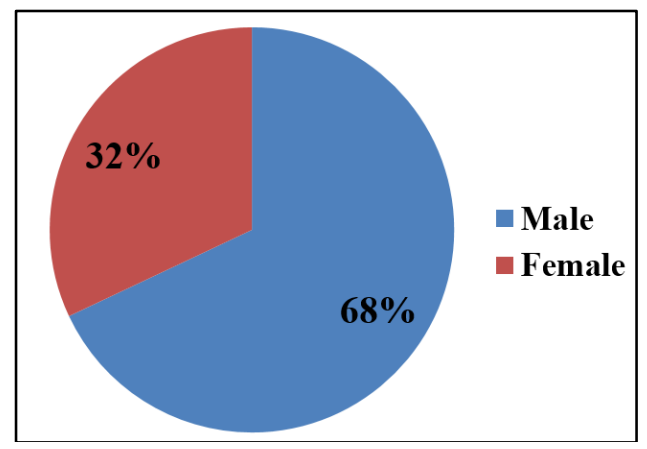

Fig. 1: Gender distribution of subjects
Out of the total patients majority $29(40.27 \%)$ were in age group 41-50 years. Only07 (9.72\%) patients were less than 40 years old and $10(13.88 \%)$ above 60 years age. (Table 1)

Table 1: Age group of patient in the study

\begin{tabular}{|l|c|c|}
\hline Age in years & No. of patient & Percentage \\
\hline$<40$ & 7 & 9.72 \\
\hline $41-50$ & 29 & 40.27 \\
\hline $51-60$ & 26 & 36.11 \\
\hline $61-70$ & 10 & 13.88 \\
\hline Total & 72 & $100 \%$ \\
\hline
\end{tabular}

The right foot was involved in $43(59.72 \%)$ patients, $27(37.5 \%)$ patients had left foot involved and only $2(2.77 \%)$ patients had bilateral involvement. (Table 2)

Table 2: Affected side of subjects studied

\begin{tabular}{|l|c|c|}
\hline \multicolumn{1}{|c|}{ Side } & No. of Patients & \% \\
\hline Right & 43 & 59.72 \\
\hline Left & 27 & 37.5 \\
\hline Bilateral & 2 & 2.47 \\
\hline Total & 72 & 100 \\
\hline
\end{tabular}

In $37(51.38 \%)$ cases the duration of diabetes was not mentioned in the case records. The duration of diabetes in most cases 23 (31.94\%) was of 10-20 years duration. (Table 3)

Table 3: Duration of diabetes

\begin{tabular}{|l|c|c|}
\hline \multicolumn{1}{|c|}{ Duration } & $\begin{array}{c}\text { Number of } \\
\text { patients }\end{array}$ & $\boldsymbol{\%}$ \\
\hline Not mentioned & 37 & 51.38 \\
\hline$<10$ years & 11 & 15.27 \\
\hline$>10$ years & 24 & 33.33 \\
\hline Total & 72 & 100 \\
\hline
\end{tabular}

We searched for diabetic foot cases in all six units of surgical wards and following table 4 shows unit wise case distribution.

Table 4: Unit wise case distribution of diabetic foot subjects

\begin{tabular}{|l|c|}
\hline Unit & No. of cases \\
\hline Unit I & 18 cases \\
\hline Unit II & 9 cases \\
\hline Unit III & 8 cases \\
\hline Unit IV & 10 cases \\
\hline Unit V & 12 cases \\
\hline Unit VI & 15 cases \\
\hline Total & 72 cases \\
\hline
\end{tabular}

All the case records showed diagnosis of diabetic foot in addition to associated varied spectrum of lesions such as ulcer, abscess, cellulitis, osteomyelitis, necrotysing fascitis, wet/dry gangrene, peripheral 
arterial disease, charcot neuro arthropathy etc. in various combinations.

Debridement was the commonest surgical procedure done in 48 cases $(66.66 \%)$ followed by toe/toes amputation done in 10 cases $(13.88 \%)$. A total of $8.33 \%$ patients underwent major amputation (below knee amputation + above knee amputation). The overall amputation (minor and major) accounted for $55.55 \%$ cases. (Table 5)

Table 5: Surgical procedures done on diabetic foot patients

\begin{tabular}{|l|c|c|}
\hline \multicolumn{1}{|c|}{ Surgery } & $\begin{array}{c}\text { No. of } \\
\text { patients }\end{array}$ & $\%$ \\
\hline Debridement & 48 & 66.66 \\
\hline Toe/ toes amputation & 10 & 13.88 \\
\hline TMT & 5 & 6.94 \\
\hline Mid foot amputation & 3 & 4.16 \\
\hline BKA & 4 & 5.55 \\
\hline AKA & 2 & 2.77 \\
\hline Total & 72 & 100 \\
\hline
\end{tabular}

Affected side (ipsilateral) foot was examined in all patients (100\%). Evaluation of opposite foot (contralateral) was done in only 42 cases (58\%) where as 30 cases $(42 \%)$ were left unexamined. (Fig. 2, 3)

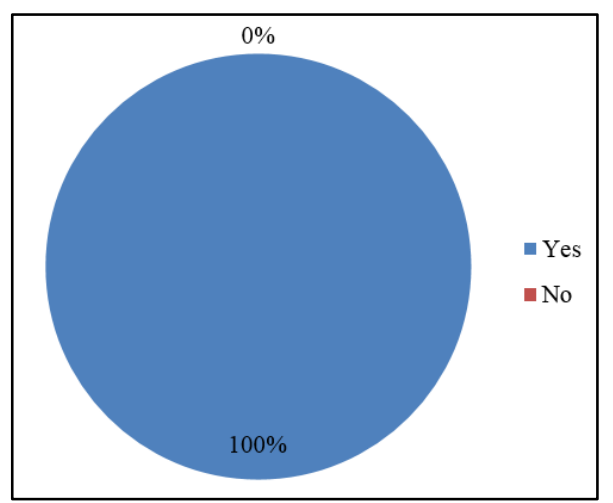

Fig. 2: Distribution of patients having ipsilateral foot examined

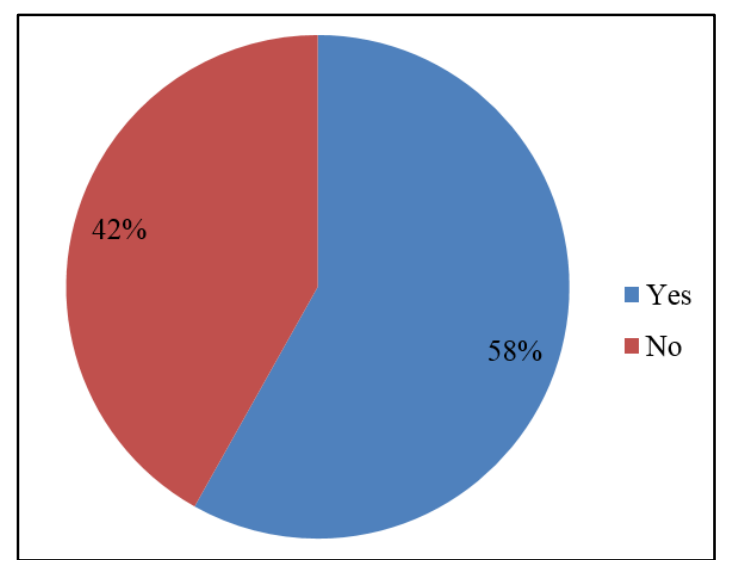

Fig. 3: Distribution of patients having contralateral foot examined
During evaluation of triple component distribution of ipsilateral foot it was found all $(100 \%)$ of affected foot were inspected (look component), 62 (86.11\%) cases had atleast one of the pulses checked (feel component) and only 18 cases $(25 \%)$ cases had foot sensation tested by using any of the modality monofilament/tunning fork. In 54 cases (75\%) no record of test component was mentioned. On the opposite foot (Contralateral) 42 (58\%) feet were inspected (look component), and pedal pulses felt (feel component) in similar number of patients were as in none of the patients sensations were documented (test component)

Table 6: Distribution of components of examination on ipsilateral side of foot

\begin{tabular}{|l|c|c|}
\hline Contra lateral & $\begin{array}{c}\text { No. of patients }(\mathbf{n}= \\
\text { 72) }\end{array}$ & $\%$ \\
\hline Look & 72 & 100 \\
\hline Yes & 0 & \\
\hline No & 62 & 86.11 \\
\hline Feel & 10 & 13.88 \\
\hline Yes & 18 & 25 \\
\hline No & 54 & 75 \\
\hline Test & \multicolumn{3}{|}{} \\
\hline Yes & \multicolumn{3}{|l}{} \\
\hline No &
\end{tabular}

Table 7: Distribution of components of examination on contra lateral side of foot

\begin{tabular}{|l|c|c|}
\hline Contra lateral & $\begin{array}{c}\text { No. of patients } \\
(\mathbf{n = 7 2})\end{array}$ & $\%$ \\
\hline Look & 42 & 58 \\
\hline Yes & 30 & 42 \\
\hline No & 42 & 58 \\
\hline Feel & 30 & 42 \\
\hline Yes & 0 & 0 \\
\hline No & 72 & 100 \\
\hline Test & \multicolumn{3}{|c|}{} \\
\hline Yes &
\end{tabular}

\section{Discussion}

In diabetic population development of peripheral neuropathy plays a pivotal role in formation of diabetic foot ulcer and subsequent amputation and hence detection of loss of protective sensation is a must to segregate high risk feet for interventional modalities and allocate medical resources and personell to them for amputation prevention. ${ }^{10}$ Despite knowledge of the fact that diabetic foot ulceration can be prevented by thorough routine foot evaluation, in majority cases foot assessment is largely incomplete and also missed.

In a study by Berbayer ${ }^{11}$ on limb care in diabetic patients from Canada only $40 \%$ patients had annual examination by doctor just once. In another study from Tanzania by Chiwanga $^{12}$ et al, $27,5 \%$ feet were 
examined by a doctor. Salem et $\mathrm{al}^{13}$ in their study on Asian subjects found their foot examination was missed in $61.9 \%$ patients. In a study by Kumar et $\mathrm{al}^{14}$ they reported only $13.8 \%$ of diabetic feet were examined. In fact there are data to suggest that proper foot evaluation was done only in $20 \%$ of the time.

A cilinical audit by Ismail et al ${ }^{15}$ also reported paucity of adequate foot evaluation with none of the feet tested for sensation. In a study by Santosh et $\mathrm{al}^{16}$ on diabetic in- patients in medical wards only $7.7 \%$ of diabetic patients were examined and findings of component distribution of Amit Jains triple assessment reported $6.2 \%$ feet inspected, $1.5 \%$ pedal pulses felt, none had sensation tested and contralateral foot was not examined in any of the subjects. In Jain et $\mathrm{al}^{17}$ series on inpatients of surgical wards it was found that in $94 \%$ cases affected foot was inspected, 58\% had pedal pulse evaluated and in only $2 \%$ sensation was tested; in contrast to contralateral foot where $2 \%$ cases were inspected, $2 \%$ had pedal pulses palpated and none evaluated for sensation testing.

In our study we found that all patients were examined on affected side and only 58\% had opposite foot examined. On triple assessment of component distribution $100 \%$ feet were inspected, in $86 \%$ pedal pulses were felt and only $25 \%$ tested for sensations with no record of test component available in $75 \%$ subjects on ipsilateral side. On contralateral side $58 \%$ of each were inspected and pedal pulses evaluated but none had foot sensation documented. All patients were admitted to surgical wards based on inspection and palpation findings and also choice of surgical procedures and outcome was based on local examination findings; hence relatively better and adequate evaluation was done in surgical wards.

\section{Conclusion}

Regular and adequate routine foot examination compiled with good foot care are cornerstone in amputation prevention in diabetic foot patients. A rapid simple inexpensive screening tool ensures and enables foot examination by health care professional. Amit Jains triple assessment fulfils all above criteria and is an essential part of wholesome foot evaluation carried out by health care worker. It promotes early identification of high risk feet and also helps in proper diagnosis and categorization of foot lesions by effectively addressing triopathy in diabetic foot.

\section{References}

1. International Diabetes Federation. Diabetes Atlas (5th edn). 2011

2. Pendsey SP. Understanding diabetic foot. Int J Diabetes Dev Ctries. 2010;30(2):75-9.

3. Jeffcoate WJ, Lipsky BA, Berendt AR, Cavanagh PR, Bus SA, Peters EJ, van Houtum WH, Valk GD, Bakker $\mathrm{K}$. Unresolved issues in the management of ulcers of the foot in diabetes. Diabet Med. 2008;25:1380-1389.
4. Boulton AJ, Vileikyte L, Ragnarson- Tennvall G, Apelqvist J. The global burden of diabetic foot disease. Lancet. 2005;366:1719-1724.

5. Seid A, Tsige Y (2015) Knowledge, practice and barriers of foot care among diabetic patients attending Felege Hiwot referral hospital, Bahir dar, Northwest Ethopia. Adv Nurs. Article ID: 934623.

6. Kuhnke JL, Botros M, Elliott J. The case for diabetic foot screening. Diabetic Foot Canada. 2013;1(2):8-14.

7. Murphy CA, Laforet K, Da Rosa P. Reliability and predictive validity of Inlow's 60 second diabetic foot screen tool. Adv Skin Wound Care. 2012;25(6):261-6.

8. Woodbury MG, Sibbald RG, Ostrow B. Tool for rapid easy identification of high risk diabetic foot: Validation and clinical pilot of the simplified 60 second diabetic foot screening tool. Plos One. 2015;10(6):e0125578.

9. Jain AKC. Amit Jain's triple assessment for foot in diabetes- The simplest and the fastest screening tool in the world. IJMSCI. 2017;4(6):3015-9.

10. Lavery LA, Armstrong DG, Vela SA, Quebedeaux TL, Fleischli JG: Practical criteria for screening patients at high risk for diabetic foot ulceration. Arch Intern Med. 1998;158:157-162.

11. Berbrayer D. Self-care among diabetic amputee. Int $J$ Diabetes Clin Res. 2015;2:1.

12. Chiwanga FS, Njelekela MA. Diabetic foot: prevalence, knowledge, and foot self-care practices among diabetic patients in Dar es Salaam, Tanzania: a cross-sectional study. J Foot Ankle Res. 2015;8:20.

13. Saleem S, Maken ZH, Farooq R, Malik ZI. The great diabetic foot debate: what part does the physician inpatients foot care knowledge. Ann Pak Inst Med Sci. 2016;12(2);72-6.

14. Kumar D, Khan MU, Mobin A. The awareness and practices of foot care in adult diabetic patients attending University Hospital. J Diabetes Metab. 2016;7:11.

15. Ismail I, Dhanapathy A, Gandhi A, Kannan S. Diabetic foot complication in a secondary foot hospital: A clinical audit. AMJ. 2015;8(4):106-12.

16. Santosh MP, Amit Kumar C. Jain, Gopal S. Determining foot evaluation done in Diabetic in patients admitted in medical wards and analyzing it through Amit Jain's triple assessment for foot in diabetes. Int Surg $J$. 2018;5(7):2465-2469.

17. Jain AKC, Jabbar S, Gopal S. Analysis of the ipsilateral and the contralateral foot in patients admitted with diabetic foot complication through Amit Jain's triple assessment for foot in diabetes. Int Surg J. 2018;5:221722.

How to cite this article: Prajapati R, Singh M, Verma D. Triple assessment for addressing triopathy in diabetic foot - Rapid screening tool for amputation prevention in govt. Hospital setting. Indian J Orthop Surg. 2018;4(3):302-305. 